\title{
Molecular composition and quality/taste of olive oil: monoterpenes and natural phenols
}

\author{
Armandodoriano Bianco*, Anna Maria Serrilli, and Cristiana Melchioni \\ Dipartimento di Chimica, Istituto di Chimica Biomolecolare del CNR. Università degli Studi di \\ Roma "La Sapienza” Piazzale Aldo Moro 5, 00185 Roma (Italy) \\ E-mail: armandodoriano.bianco@uniroma1.it
}

\section{Dedicated to Professor Atta-ur-Rahman in the occasion of its $65^{\text {th }}$ birthday}

\begin{abstract}
This article deals with the monoterpenic and phenolic micro-components present in olives and the manner in which these compounds are transferred into the olive oil. Of particular interest is the molecular structure of the isolated compounds and the transformations of oleuropein during the technological process of olive oil preparation. The existing relationship between the quality/taste of the olive oil and these micro-components are also discussed.
\end{abstract}

Keywords: Olive,olive oil,monoterpenes,natural phenols

\section{Content}

1. Olive and olive oil

1.1 Glycosidic components present in the olive (leaves and fruits)

1.2. Biochemical transformations of the phenolic and glycosidic components.

\section{Introduction}

Olive oil is the favourite seasoning for all the people living around the basin of the Mediterranean Sea. The use of olive oil for food has very ancient origins and the references to this as a food are found in the first historical documents. Olive oil also had in antiquity other uses, some of which are still utilized today. It was used for illumination, and the archaeological finds of oil lamps are innumerable and testify to the use of the oil lamps at each social level and for innumerable different environments. It was used also as an ointment, thinking to the Lisippo's sculptures of athletes anointing their bodies with this oil. 
Olive oil had a fundamental role as a natural extract in the Mediterranean civilization. In fact the $O$. europaea plant is usually present in the Mediterranean basin, testifying to ancient cultivations. In the past, outside the Mediterranean area, there was not a significant diffusion of the O. europaea plant and therefore of olive oil. It is a historical fact that the large civilizations of the past have all developed in the Mediterranean basin or in geographically similar areas. Is it a case that the Greek civilization first, then the Roman and successively the Arabic civilization have bloomed in a geographical zone in which olive oil had such a fundamental role? And hasn't God perhaps selected a typically Mediterranean country for his terrestrial abode? Is it still a case that people that usually employed animal fats for the same purposes have not developed any important civilization? Applying to the northern Europe people, we used to refer to the Barbarians. In each case olive oil has accompanied the development of civilization of people that have carried out an important role in the history of the humanity. A temporary tarnishing of the importance of olive oil, especially as a food, happened with the coming of the modern Era. Animal fats have been preferred by big economic powers, such as the United States of America, considered animal fats as the only existing fats. Even vegetable fats have been hydrogenated to margarines, absolutely useless food, in order to make them more similar to the animal solid fats. However, the knowledge and the discovery of a series of serious pathologies due to the exclusive use of animal fats has re-proposed olive oil as a possible and valid alternative food. All the scientific searches have put in evidence a series of positive effects due to the use of olive oil as a food. The so-called "Mediterranean diet" constitutes the present top of this search; it provides the use of the olive oil as seasoning and, what is more important, it has been formulated by those people that always showed a preference to employ of animal fats for feeding. Owing to the poor attention devoted to olive oil in the '50 and '60 years, the modalities of production of olive oil are similar to those handed down from tradition. Therefore the quality of the olive oil produced was tightly related to the "personality" of the olive grower and of the olive press worker. Just when olive oil is engaging an elective position, it is necessary to face, from a scientific point of view, the problems concerning the olive oil quality and the organoleptic factors correlated such as taste. The problem taste/quality of the olive oil deals not only with the main components but also the minor components present in the olive oil. It is well-know that the colour of olive oil derives from variable quantity of xanthophylls and chlorophylls that melt in the phase "oil" during the squeezing. Besides the colour, these components give a significant contribution to the taste of the olive oil according to their percentage presence. However, as regards to the taste/quality of the olive oil, the micro-components that have a very important role are those arising from the natural compounds of type phenolic and terpenic, present in the olive pulp in free form or, more frequently, in the glycosidic form.

The role played by these micro-components towards the quality/ taste have not been carefully examined. Certainly the taste of the olive oil is dependent on the nature and the quantity of the phenolic and terpenic micro-components present in the oil. Their presence in the oil depends on a series of different factors. First of all, it depends on the degree of maturation of 
the olives. The nature of the ground in which the cultivation exists, the variety of the olive plant, the climate and all the other factors tied up to the habitat are also very important.

Moreover the presence and the relative quantity of these micro-components also depend on the percentage of water, present in the olive oil, in which such micro-components have been distributed according to their relative solubility.

Therefore the knowledge of the molecular structure of the phenolic and terpenic microcomponents is an essential factor for a rational study of the factors that influence the taste and, mainly, the quality of the olive oil.

Furthermore the nature of the phenolic and terpenic micro-components present in the olive oil is dependent on the process of oil preparation.

In fact, a series of particularly active enzymes are present in the olive, among which the most important are the glycosidases and the hydrolases. Many of the phenolic and terpenic micro-components present in the olive oil have both a glycosidic and an ester function. Therefore, during the squeezing, when olives are shattered and all the cellular material is mixed, the hydrolytic enzymes cleave the glycosidic and the ester bonds. The result of this enzymatic action is the liberation of a saccharidic fraction, having a high polarity, and another phenolic and terpenic fraction whose polarity depends on the structure of these micro-components.

In practice, during the squeezing all the glycosidic parts are present in the aqueous phase, while the phenolic and terpenic components are distribute between the aqueous phase and the "oil" phase according to their polarity and lipophilicity. After the separation of the saccharidic residue the aglycons of phenolic and terpenic nature can also undergo some spontaneous transposition reactions catalyzed by the environment of the olive paste. For example, the slightly acid $\mathrm{pH}$ catalyzes all those molecular reactions commonly called "acid-catalyzed". Therefore the transformed micro-components are present in the olive oil with the micro-components naturally present in the olives.

All of these micro-components constitute a characteristic mark of the olive oil that depends, as noted above, on different factors such as the variety of the olive plant, the habitat, the squeezing formality and of course the season, etc.

The knowledge of these data (nature and relative quantity of the phenolic and terpenic micro-components naturally present or proceeding from biotransformation) will allow having both a precise picture of the olive oil composition and an influence on such data.

Therefore, the knowledge of the biochemistry of the olive oil allows one to have objective data related to the quality and the taste of olive oil.

The phenolic and terpenic micro-components present in the leaves and in the fruits of the olive plant could allow to verify what components are contemporary present in the oil produced; the quantity of such compounds could be put in collection with the process of drupe maturation. Furthermore, it is possible to examine those compounds which are transferred into olive oil and in which phase (water or olive oil), the relative quantity of such compounds, which compounds are biotransformed during the phase of olive oil preparation and into which products they have been transformed and their relative quantity. 
The different varieties of cultivar of olive plants and different environments of cultivation allow a comparison of the results obtained from different environments and with different cultivations, besides they allow the possibility to propose parameters usable to the goals of a "control of the origin."

The case of different formalities of squeezing could contribute to give objective directives in the formality of squeezing, always in order to suggest a "control of origin."

\section{Olive and olive oil}

\subsection{Glucoside components in the olive (leaves and fruits)}

Among the different components which are already known in the olive plant, the first one is the oleuropein (1). This is the most important component of the glucosidic fraction of the Olea europaea from the quantitative point of view and from the historical point of view. In fact the oleuropein is the first secoiridoid isolated from all over the world. In the oleuropein molecule, both a monoterpenic and an orhto-diphenolic unit are present. ${ }^{1}$

Panizzi et al. ${ }^{2}$ isolated oleuropein in the $50 \mathrm{~s}$. They determined its structure and established that this compound was one of the most important compouinds responsible for the bitter taste of the fruits and the leaves of olive plant and that it was the active responsible for the known hypotensive action of the extracts of the olive plant. Recently the accurate quantitative determination of oleuropein content in olive and olive oil was proposed by Sindona el al. ${ }^{3}$

The oleuropein $\mathbf{1}$ is a secoiridoid glucoside that esterifies a dihydroxy-phenyl-ethyl alcohol. Two of its by-products are also present in the olive plant together with the oleuropein $\mathbf{1}$ and the mono-demethyl-derivatives $\mathbf{2}$ and $\mathbf{3}$.

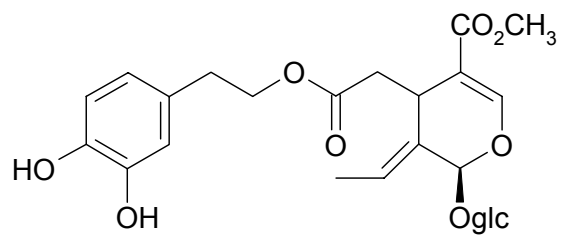

1<smiles>C/C=C1/C(CC(=O)O)C(C(C)=O)=CO[C@H]1OC</smiles>

3

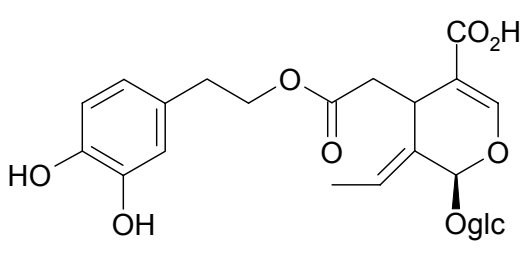

2

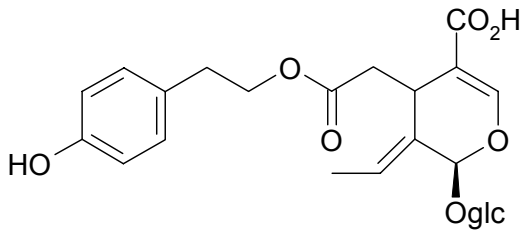

4 
Compound $\mathbf{2}$ is demethyl-oleuropein, which differs from oleuropein $\mathbf{1}$ in having a free carboxylic group on the pyranosic ring.

Compound $\mathbf{3}$ is the oleoside methyl ester, known also as a glucoside of the elenolic acid, in which the carboxyl that esterifies the dihydroxy-phenyl-ethanol in the oleuropein $\mathbf{1}$ is here the free functionality.

The two acid compounds $\mathbf{2}$ and $\mathbf{3}$ are two indicators of maturation of the olives. Their relative quantity, as regards to the oleuropein 1, increases in fact as soon as the maturation proceeds, while the quantity of oleuropein decreases. This datum is in connection with the increase of the activity of the hydrolytic enzymes with the progress of the maturation, particularly to the activity of the esterases, responsible of the hydrolysis of the two ester bonds of the oleuropein. ${ }^{4}$

Other hydrolytic enzymes, such as the glycosidases, increase their activity with the maturation and therefore they are responsible, for instance, of the presence of meaningful quantity of dihydroxy-phenyl-ethanol in the mature olive. Moreover, other compounds structurally correlated to the oleuropein $\mathbf{1}$ are present in the olive plant.

The ligstroside $4^{5}$ differs from the oleuropein 1 in the presence of a tyrosol residue instead of dihydroxy-phenyl-ethylic alcohol.

The dimethylester of the oleoside 5, also known as glucoside of the methylester of the elenolic acid, contains the two acidic functions of the oleuropein esterified with a residue of methanol. ${ }^{6}$ The oleuroside $\mathbf{6}$ is an isomer of the oleuropein, differing ${ }^{7}$ from $\mathbf{1}$ in the exocyclic double bond position.

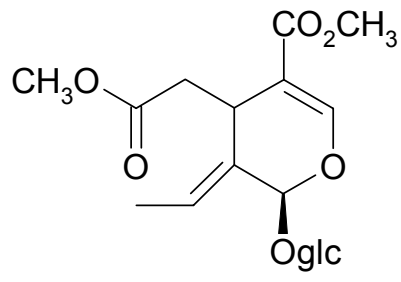

5

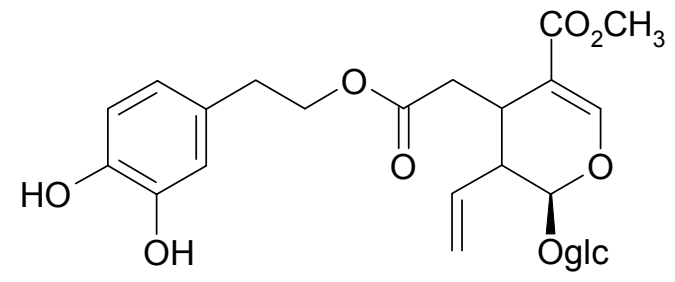

6

Then several glucosidic compounds are present in connection with the dihydroxy-phenylethanol. The first one is the cornoside 7, a glucoside of a hemiquinoid isomer of the dihydroxyphenyl-ethyl alcohol ${ }^{8}$. 


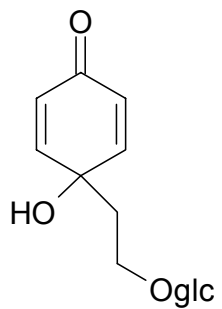

7<smiles>O=C(O)c1ccc(CCO)cc1O</smiles>

$8 a$<smiles>COc1cc(CCO)ccc1O</smiles>

$8 b$<smiles>COCCc1ccc(O)c(O)c1</smiles>

$8 c$

The others are the $\beta$-glucopiranosyl-derivatives of dihydroxy-phenyl-ethanol $\mathbf{8 a}, \mathbf{8 b}$ and 8c. The structure of compound $\mathbf{8 a}$ has been demonstrated by spectroscopic analysis by Bianco et al. ${ }^{9}$ Compounds $\mathbf{8 b}$ and $\mathbf{8 c}$ were previously described in O.europaea.

The increase of the hydrolytic activity of $\beta$-glycosidase, as well as that of the esterase, has been put in evidence by the presence in the olives of different components deriving from an enzymatic process of hydrolysis of the glycosidic structures: first of all the two not glucosidic secoiridoids 9 and $10 .{ }^{6}$ They derive from the oleuropein 1 by the enzymatic hydrolysis and by the transposition depicted in the scheme 1.<smiles>C/C=C1\C(O)OC=C(C(C)=O)C1CC(=O)OCCc1ccc(O)c(O)c1</smiles>

1<smiles>CC(=O)C1=COC(C)[C@H](CC(=O)OCCc2ccc(O)c(O)c2)[C@H]1C</smiles>

10<smiles>CC(=O)OCCc1ccc(O)c(O)c1</smiles>

9

\section{Scheme 1}

Secondly, the presence of the dihydroxy-phenyl-ethyl alcohol, whose concentration increases with the maturation, could be derived from the ester bond hydrolysis of the oleuropein catalyzed by esterase ${ }^{4}$ or from enzymatic hydrolysis, catalyzed by $\beta$-glucosidase, of the sugar on the phenolic glucoside $\mathbf{8}$.

Another new compound isolated from the olive plant is the product 11, the di-galactoside of a poly-unsaturated diester of the glycerol. ${ }^{10}$ 


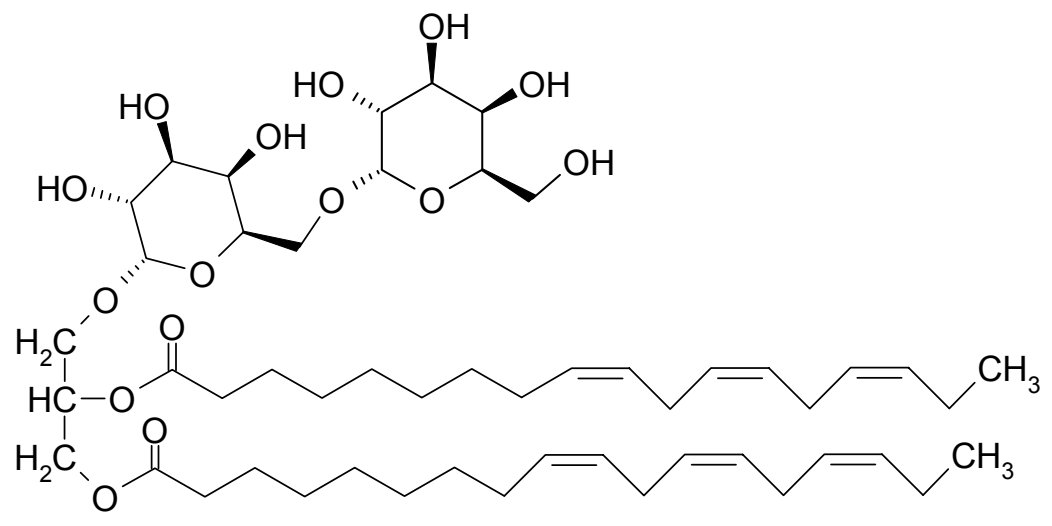

11

The particularly interesting datum of this structure is that the poly-unsaturated acid that esterifies the glycerine is $\alpha$-linolenic acid. The product $\mathbf{1 1}$ is the principal component of a group of glycosides of poly-unsaturated di-esters of glycerine, present in the leaves and in the olives and whose concentration seems to decrease with the maturation, even if in a not marked way.

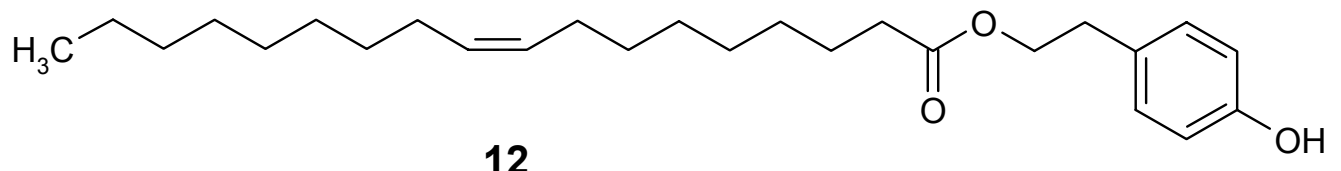

In the end ,two new esters of tyrosol $\mathbf{1 2}^{11}$ and of hydroxyl-tyrosol $\mathbf{1 3}^{12}$ have been isolated from olives. Both compounds indicate the interesting metabolic activity of O.europaea.<smiles>COC(=O)C(O)CC(=O)OCCc1ccc(O)c(O)c1</smiles>

13

Compound 12 is the oleic ester of tyrosol and it appears to be present mainly in olives. Compound $\mathbf{1 3}$ is the malic ester of hydroxy-tyrosol and is another of ester of tyrosol derivatives present in O.europaea.

\subsection{Biochemical transformations of the phenolic and glycosidic components}

During the squeezing of the olives for the preparation of the olive oil, a fundamental phenomenon occurs which determines the quality of the olive oil, particularly in connection with the organoleptic characteristics. 
In the pulp of the olives obtained by shattering, the vegetable cells are broken come routs and all the present cellular material is mixed. Particularly the hydrolitic enzymes (glycosidases and esterases), that are stronger active in the mature olive, are placed in contact with all the natural organic substances present in the olives, among which the substances above mentioned. ${ }^{13-16}$

As regards the time between the shattering of the olives and the squeezing and the environment temperature to which the olive paste is left, the hydrolytic enzymes modifies oleuropein and to a lesser extent the glucosidic and ester bonds without any biological control.

The triglyceride of the oleic acid, that is the main component of the olive oil, in this phase can be partially separated furnishing mono- and di-glycerides and also free acids that influence strongly the organoleptic qualities of the oil.

The oleuropein 1, by enzymatic hydrolysis of the glucose, changes into its aglycon 1a (see scheme 2) or by esterases action loses the dihydroxy-phenyl-ethanol and methanol (compound 1b), or suffers the break of the glucosidic and ester bonds (compound 1c).

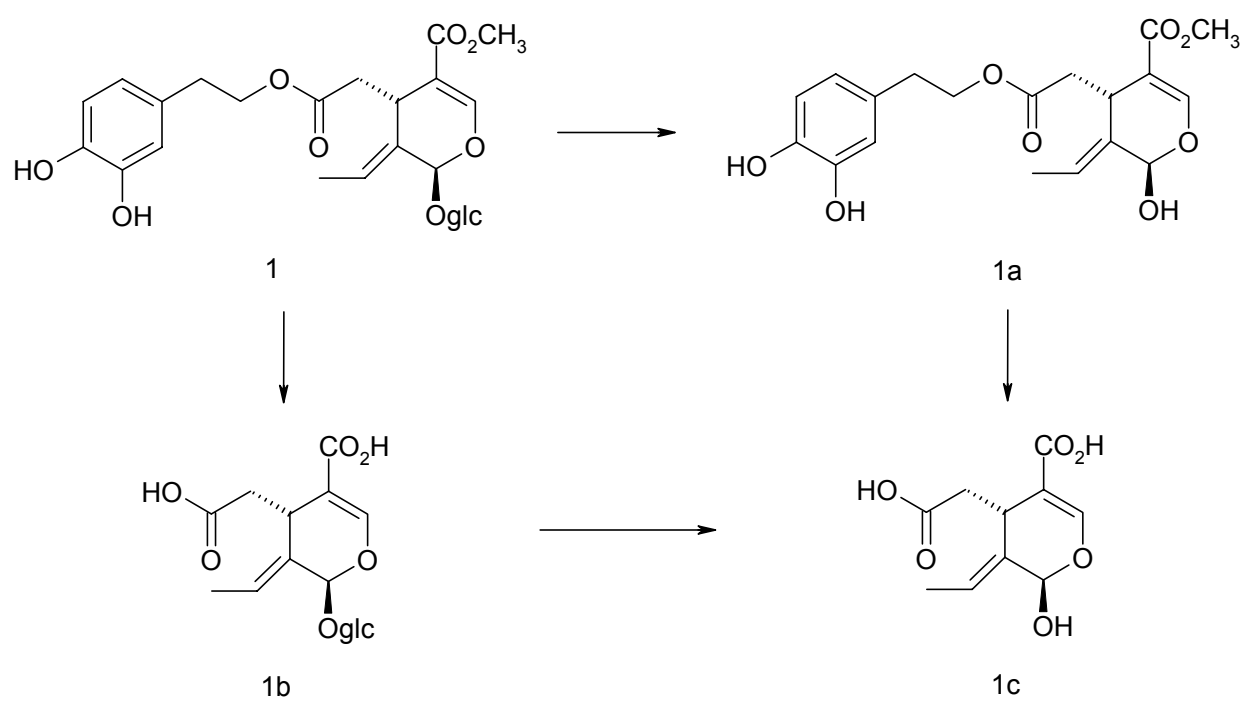

\section{Scheme 2}

The glucose, with the methyl alcohol, after the squeezing is recovered totally in the waters of vegetation, while the dihydroxy-phenyl-ethyl alcohol will divide between water and olive oil according to the coefficient of division to the temperature of squeezing and therefore it will also be present in the olive oil.

The mixtures that, like the dihydroxy-phenyl-ethanol, have any orhto-diphenolic function, are excellent compounds for the quality of the olive oil. In fact they are easily oxidizable according to the scheme 3 . 


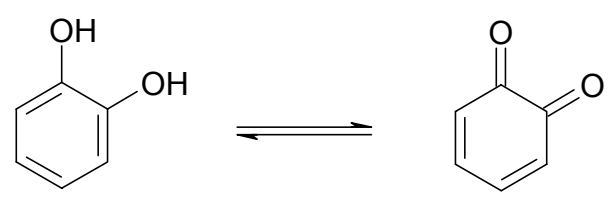

\section{Scheme 3}

The presence in the olive oil of compounds containing the orhto-diphenolic function is therefore responsible of the resistance of the olive oil to the oxidation.

All the mixtures which contain the ortho-diphenolic function are therefore excellent products and they can also be indicative of the state of maintenance of the olive oil, because any industrial manipulation eliminates immediately and totally such diphenolic component of the olive oil.

In the oil it is always present a more or less small quantity of water of vegetation (the more or less veiled olive oils). The presence of this watery phase enriches the oil of more hydrophilic compounds, among which particularly ortho-diphenols such as the dihydroxy-phenyl-ethanol that therefore confers to the veiled olive oils a better resistance to the oxidation.

In the hydrolysis of the oleuropein 1 the monoterpenic part also frees (compound type 1c in the Scheme 2). This mixture is moderately polar, so it may pass in the olive oil in the some way, always in connection to its coefficient of division with the water, but it might also and this is more important, give place to molecular transformations catalyzed by the slightly acid $\mathrm{pH}$ of the environment constituted from the olive paste.

In vitro the mixture 1c changes ${ }^{17}$ into the mixture 1d (see Scheme 4 ) much less polar and therefore more soluble in the olive oil.<smiles>C/C=C1/C(O)OC=C(C(=O)O)[C@@H]1CC(=O)O</smiles>

$1 \mathrm{c}$<smiles>C=CC(=O)C[C@@H](C=O)/C(C=O)=C\C</smiles>

$1 d$

\section{Scheme 4}

Compound 1d could be therefore proposed as an indicator of quality of the olive oil. Molecular transformations catalyzed by the environment that takes place in the olive paste can also happen on simpler products such as the cornoside 7. In the Scheme 5 is described the process of transformation observed in vitro that carries to the formation of the compound $\mathbf{7 a}$. 

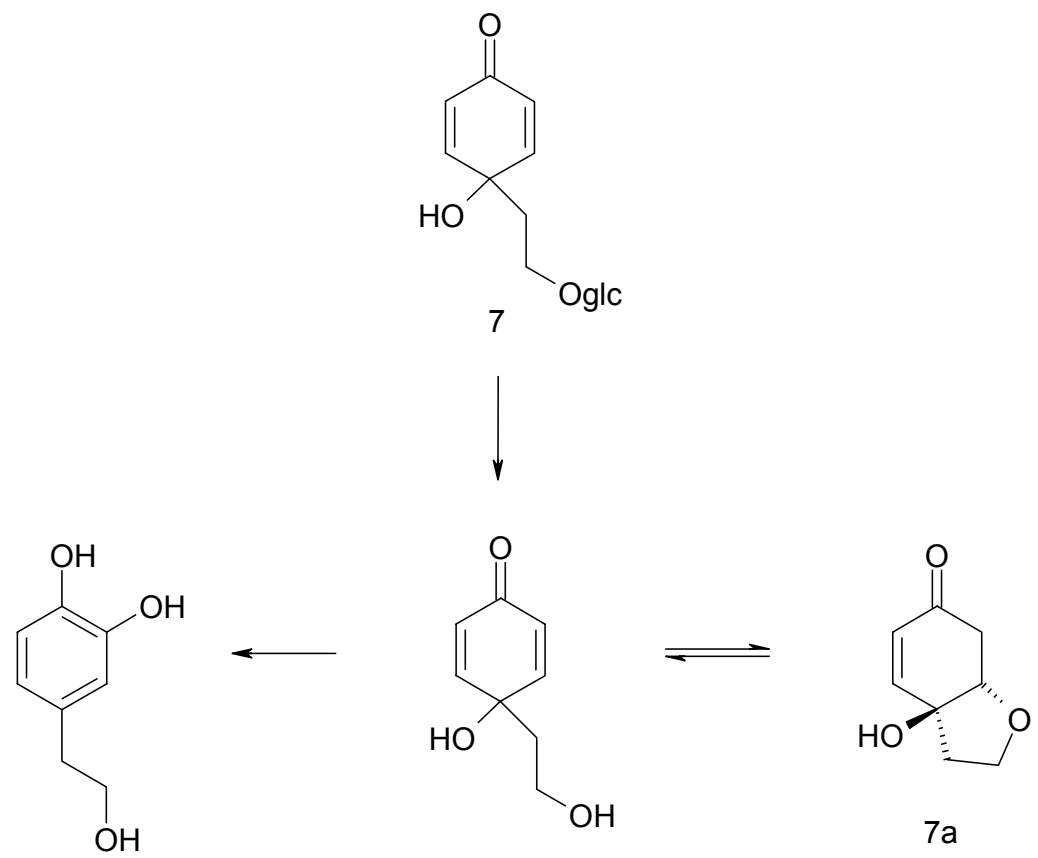

\section{Scheme 5}

Also 7a could be an indicator of quality, and as it is much less polar it passes into the olive oil.

The glucosidic diglycerides, like the compound $\mathbf{1 1}$ divide between water and oil in comparable quantity because they have either a hydrophilic part (the glucose) or a strongly lipophilic part (the two residues of unsaturated fatty acids), behaving practically as a not ionic soap.

In the squeezing phase the glucose linkage can be hydrolyzed and so the diglyceride becomes free and it constitutes a member of the small diglyceride fraction of the olive oil.

The hydrolysis of the ester function is slower, but detectable quantities of monoglycerides are present in the olive oil. ${ }^{18-22}$

Therefore the glucoside $\mathbf{1 1}$ also, and the diglyceride derived from its hydrolysis, can be proposed as markers of typicalness and of quality of the olive oil. In fact the quantities of the glycoside 11 depend on the degree of maturation of the olives, while those of the diester corresponding, derived from the hydrolysis of the glycosidic function depend on the formalities of the squeezing. Then as the fatty acid is characterized by a high degree of unsaturation, it differs clearly from the other unsaturated acids present in the olive oil and so it can be easily separated (for example by magnetic nuclear resonance) from the other di- and mono-esters of the glycerine.

\section{Acknowledgements}

Financial support from CNR. 


\section{References and Notes}

1. Bianco A., Ramunno A. Atta-ur-Rahman Ed., Studies in Natural Products Chemistry, Elsevier, 2006 Vol 33 p.859-903.

2. Panizzi L., Scarpati M.L., Gazz. Chim. Ital. 1960, 90, 1449-1485.

3. De Nino A., Di Donna L., Mazzotti F., Muzzalupo E., Perri E., Sindona G., Tagarelli A. Anal.Chem. 2005, 77, 5961-5964.

4. Amiot M.J., Fleuriet A., Macheix J.J. Phytochemistry 1989, 28, 67-69.

5. Asaka Y., Kamikawa T., Kubota T., Sakamoto T. Chem. Letters 1972, 141.

6. Gariboldi P., Jommi G., Verotta L.. Phytochemistry 1986, 25, 865-869.

7. Kuwajima H., Uemura T., Takaishi K., Inoue K., Inouye H. Phytochemistry 1988, 27, 17571759.

8. Bianco A., Lo Scalzo R., Scarpati M.L. Phytochemistry 1993, 32, 455-457.

9. Bianco A., Mazzei R.A., Melchioni C., Romeo G., Scarpati M.L., Soriero A., Uccella N. Food Chemistry 1998, 63, 461.

10. Bianco A., Mazzei R.A., Melchioni C., Scarpati M.L., Romeo G., Uccella N. Food Chemistry 1998, 62, 343.

11. Bianco A., Melchioni C., A. Ramunno, G.Romeo, N.Uccella Natural Products Research, 2004, 18, 29-32.

12. Bianco A., Chiacchio M.A., G.Grassi, D.Iannazzo, R.Romeo Food Chemistry, 2006, 95 , 562-565.

13. Bianco A., Muzzalupo I., Piperno A., Romeo G., Uccella N. J. Agric. Food Chem. 1999, 47, 3531 .

14. Bianco A., Chiacchio U., A.Rescifina, G.Romeo, N.Uccella J.Agric.Food Chem, 1997, 45, 4281.

15. Bianco A., Piperno A., Romeo G., Uccella N. J. Agric. Food Chem. 1999, 47, 3665.

16. Bianco A., Bonadies F., G.Romeo, M.L.Scarpati, A.Soriero, N.Uccella Product Research, 2006, 20 No. 3, 259-264.

17. Scarpati M.L., Lo Scalzo R.. J. Nat.Prod. 1993, 621.

18. Bianco A., Uccella N. Food Research International 2000, 33, 475

19. Bastoni L, Bianco A., Piccioni F., Uccella N.. Food Chemistry 2001, 73, 145-151.

20. Bianco A., Buiarelli F., Cartoni G., Coccioli F., Muzzalupo I., Polidori A., Uccella N. Analytical Letters. 2001, 34(6), 1033-1051

21. Bianco A., Buiarelli F., Cartoni, G., Coccioli F.,.Jasonowska R., Margherita P. Journal Separation Science, 2003, 26, 409-416.

22. Bianco A, Buiarelli F., Cartoni G., Coccioli F., .Jasonowska R., Margherita.P. Journal Separation Science, 2003, 26, 417-424. 